\title{
Institutional Experience with Electrosurgery Using Radiofrequency Inmanagement Of Idiopathic Epistaxis
}

\author{
Dr. Nanmullai ${ }^{1}$,Dr. Shanmugaashok ${ }^{2}$,Dr.Bhuvaneshwaribabu ${ }^{3}$, \\ ${ }^{I}$ (Assistant Professor,Upgraded Institute Of Otorhinolaryngology,Madrasmedicalcollege, DR.MGR \\ Medical Universitychennai, Tamilnadu,,India) \\ ${ }_{2}^{2}$ (Associate Professor,Department Of ENT, Thiruvarur Medicalcollege, DR.MGR Medical University, Chennai, \\ Tamilnadu,India), \\ ${ }_{3}^{3}$ (Postgraduate,Upgraded Institute Of Otorhinolaryngology,Madras Medical College,DR.MGR Medical \\ University,Chennai,Tamilnadu,India)
}

\begin{abstract}
This study is to find out the most common aetiology of epistaxis.Relation and correlation of nasal anatomical variations with respect to epistaxis. For earlyidentification of the cause and thereby management of idiopathic cases with sphenopalatine artery ligation using Radiofrequency. Radiofrequency is simpler, easy to perform, more useful in sphenopalatine artery ligation than conventional method.
\end{abstract}

Keywords: Epistaxis,idiopathic, Internal maxillary artery (IMA). sphenopalatine artery, sphenopalatine arteryligation (SPL), Radiofrequency(RF), Radiofrequency ligation, Electrosurgery

\section{, I. Introduction}

Epistaxis by definition is bleeding through the nose and is one of the most common and most difficult emergencies to treat[1]. About $60 \%$ of people experiences the episode at least once in life time, with less than $10 \%$ of these requiring medical attention.Most episodes are minor in nature and affected persons don't seek medical attention. In rare cases, there may be massive epistaxis also.Epistaxis can have an anterior or posterior source and can be from septum or lateral nasal wall.Intractable epistaxis remains a challenge for otorhinolaryngologists. Historically, internal maxillary artery ligation via a transantral approach and ligation of the ethmoidal vessels and the external carotid artery have been the treatment of choice when conservative management fails [5].

Over the past decade, with the widespread popularization of endoscopic sinus surgery and the better understanding of anatomy of nasal cavity, endoscopic control of the sphenopalatine artery (SPA) has been advocated as an effective alternative for the control of posterior epistaxis. This study is about use of Radiofrequency $(\mathrm{RF})$ cautery in management of idiopathic epistaxis.Radiofrequency is simpler, easy to perform, more useful in sphenopalatine artery ligation than conventional method.

\section{Materials and Methods}

Study design - Prospective

Study period -June 2014 to September 2016

Study place - Upgraded institute of otorhinolaryngology,, Madras Medical College, Government General Hospital, Chennai.

164 cases included in this study from the ENT department.Among 164 patients 33 intractable posterior epistaxis not responding to conservative management taken for surgery, (RF sphenopalatine artery ligation).

Patients above 12 years who reported with history of bleeding through the nose admitted in ward, detailed history and thorough examination of head and neck was done and site of bleeding with respect to anterior or posterior source identified. In patients with severe bleeding, anterior nasal packing and posterior nasal packing if necessary done in selected patients and all patients were admitted in the ward.Complete haematological investigations and other relevant investigations like Diagnostic nasal endoscopy(DNE), X-Ray paranasal sinuses, x-ray Chest, CT-Paranasal sinuses, ECG etc, done and other specialist opinion if needed obtained.All patients with intractable posterior epistaxis despite undergoing conservative management with anterior and posterior nasal packing selected for sphenopalatine artery ligation using Radiofrequency(RF).Informed and written consent obtained.

\subsection{Inclusion Criteria}

Age group above 12 years with history of bleeding through the nose 


\subsection{Exclusion Criteria}

Age below 12 years and patients who are not willing for study.Polytrauma with epistaxis excluded to give attention to immediate care for the patient to rule out and treat injury to other vital structures. Patients with life threatening emergencies (ie myocardial infarction etc.), Patients with any bleeding diatheses, including those receiving anticoagulant therapy excluded.Endoscopes: 0 and 30 degree, $4 \mathrm{~mm}$ Hopkins rigid nasal endoscopes (Serwel\&storz )camera, light source and bipolar Radiofrequency cautery. Anaesthesia:4\% Xylocaine decongestant nasal packs.

Table 1: Etiology Of Epistaxis

\begin{tabular}{|c|c|c|c|c|c|c|c|}
\hline S. No & Etiology & Male & $\%$ & Female & $\%$ & Total & Total \% \\
\hline 1 & Idiopathic & 52 & 25.83 & 48 & 20.83 & 100 & 60.97 \\
\hline 2 & Trauma & 6 & 5 & 4 & 3.33 & 10 & 6.84 \\
\hline 3 & Deviated nasal septumwith spur & 1 & 0.83 & 2 & 1.67 & 3 & 1.82 \\
\hline 4 & Chronic rhinosinusitis with deviated nasal septum & 2 & 1.67 & 3 & 2.5 & 5 & 3.04 \\
\hline 5 & Juvenile nasopharyngeal angiofibroma(JNA) & 9 & 7.5 & 0 & 0 & 9 & 5.48 \\
\hline 6 & Rhinosporidiosis & 3 & 2.5 & 0 & 0 & 3 & 1.82 \\
\hline 7 & Sinonasal Polyposis & 0 & 0 & 3 & 2.5 & 3 & 1.82 \\
\hline 9 & Septal Perforation & 1 & 0.83 & 0 & 0 & 1 & 0.60 \\
\hline 10 & Rhinolith & 1 & 0.83 & 0 & b & 1 & 0.60 \\
\hline 11 & Nasal malignancy & 5 & 4.17 & 1 & 0.83 & 6 & 3.65 \\
\hline 12 & Bleeding Polyps & 1 & 0.83 & 2 & 1.67 & 3 & 1.82 \\
\hline 13 & Chronic sinusitis & 0 & 0 & 2 & 1.67 & 2 & 1.21 \\
\hline 14 & Deviated nasal septum & 1 & 0.83 & 2 & 1.67 & 3 & 1.82 \\
\hline 15 & Granulation Tissue Of Septum & 1 & 0.83 & 0 & 0 & 1 & 0.60 \\
\hline 16 & Hypertension & 4 & 3.33 & 2 & 1.67 & 6 & 3.65 \\
\hline 17 & Benign mass / Inverted. Papilloma & 0 & 0 & 2 & 1.67 & 2 & 1.21 \\
\hline 18 & Haemangioma & 1 & 0.83 & 0 & 0 & 1 & 0.60 \\
\hline 19 & Iatrogenic & 2 & 1.67 & 0 & 0 & 2 & 1.21 \\
\hline 20 & Coagulation deficits & $\beta$ & 2.5 & 0 & b & 3 & 1.82 \\
\hline
\end{tabular}

\section{Description of technique}

Procedure carried under local anaesthesia (1:80,000 lidocaine and adrenaline) with pterygopalatine block. The nasal cavities decongested withlignocaine and adrenaline soaked nasal packs. Using 0 degree and 30 degree telescopes[2] and carl storz camera nasal cavity visualised. U shaped incision made on palatine bone near junction of posterior fontanelle and vertical portion of palatine bone extending from horizontal portion of middle turbinate to insertion of inferior turbinate. Posterior mucosal flap elevated.The palatine crest identified and sphenopalatine foramen found posterior to the palatine crest. The sphenopalatine artery identified and separated from surrounding structures.Using bipolar Radiofrequency, sphenopalatine artery ligated. Complete haemostasis attained. 


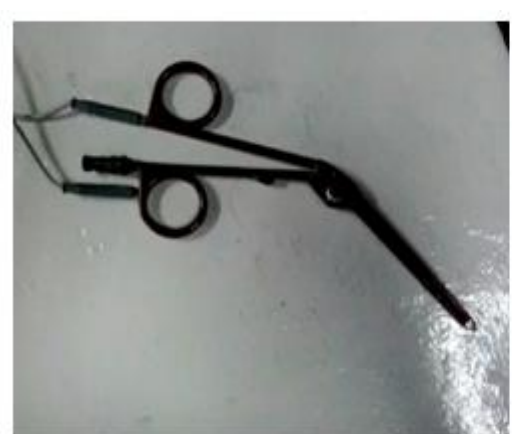

Fig 1: Bipolar Radiofrequency forceps

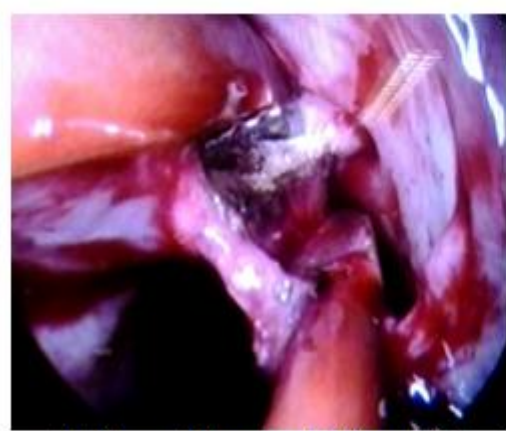

fig3: Sphenopalatine artery ligation with RF

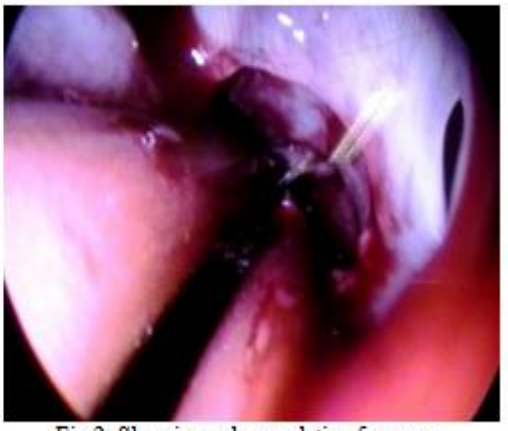

Fig 2: Showing sphenopalatine for amen

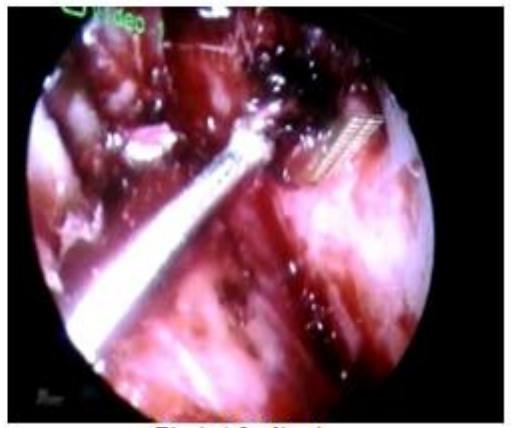

Fig 4: After ligation

\section{Discussion}

Epistaxis- bleeding through the nose is one of the most common emergencies. Most episodes are minor in nature but in some cases, there could be massive bleeding. Epistaxis can be anterior or posterior, from lateral nasal wall or septum.Management of epistaxis can be very difficult, especially when there is posterior epistaxis[5]. Posterior nasal packing is a very inconvenient method for patients and carries a high failure rate (26-52\%), failure largely since the turbinates prevent direct pressure over the bleeding point, requiring the need for repeated packing.Trauma to the nasal mucosa causes necrosis and further bleeding, starting a vicious circle. In addition, it has a high rate of complications (69\%), including injury to nasal mucosa,septal perforation synechiae. necrosis of nasal ala,perforation of palate,injury to lamina papyracea, sinusitis, orbital cellulits, and physiological and anatomical alterations in middle ear cleft.

sOne of the reasons that sphenopalatineartey (SPA) ligation has become popular is that the sphenopalatine artery (SPA) is the terminal branch of the internal maxillary artery (IMA) and is sufficiently distal to make retrograde and anastomotic blood flow from other vessels unlikely. This fact led surgeons to consider endoscopic transnasal sphenopalatine artery ligation (SPL) with radiofrequency (RF) a better way to control bleeding and minimize both morbidity and failure rates, despite the description of transantral routes to the sphenopalatine artery.With the endoscopic trans-nasal approach, the sphenopalatine artery(SPA) can be easily reached. The sphenopalatine artery(SPA) is the terminal branch of the IMA and is the dominant source of posterior nasal blood supply. Endoscopic sphenopalatine artery ligation (SPL) with RF(Radiofrequency) is technically straightforward to perform, allowing direct and secure ligation of the major vessel supplying the posterior nasal cavity, while complications associated with pterygopalatine fossa surgery are avoided. This technique reduces the potential forcomplications.

4.1 Principle of radiofrequency:Radio energy does the cutting very light. A very high frequency radio wave $0.3-2 \mathrm{MHz}$ and a fine needle or wire loop electrode which is held by the surgeon, radio energy passes between the cautery electrode and patient plate[8]. It is concentrated at the needle end or wire loop electrode, resulting in the release of energy, which produces steam within the cells, thus vaporizing them and dividing the tissues.It is a electro surgery that uses the radiofrequency alternating current to raise intracellular temperature to achieve vaporization or a combination of desiccation and protein coagulation. The electromagnetic energy is converted into kinetic energy inside the cell. The process of tissue coagulation is achieved with continuous low voltage output[8][9]. This low voltage output prevents the sticking of tissues to forceps to prevent the disruption of seal with forceps removal 


\subsection{Advantages of using RF:}

Minimumheat with no charring resulting in least tissue damage. Cutting \& fulguration is optional. Minimumblood loss \& pain. Shock proof.Local anaesthesia is not required on the surface of the skin or in superficial procedures.

Sparkless integrated circuit of latest technology for fast and continuous procedures. Pinpoint cutting capability. No postoperative crusting or risk of synechiae formation.

\section{Conclusion}

Idiopathic is the most common cause of epistaxis in this present study. Use of Radiofrequency in sphenopalatine artery ligation in controlling posterior epistaxis that is not responding to conservative management is far superior to conventional method because of its precise cutting ability and minimal tissue damage property. Recurrence after RF sphenopalatine ligation is found to be less.

No financial support received.

\section{Acknowledgment}

\section{Reference}

[1]. J.C Watkinson. Epistaxis. Rhinology 6th edition 1997 p. 4/18/1-p.4/18/8.

[2]. Marcus MJ. Nasal endoscopic control of epistaxis. A preliminary evaluation otolargyngoloy and Head \& Neck surgery. 102 : 273, 1990. )

[3]. Mackenzie D. Little's area or the locus Kiesselbachii. Journal of Laryngology.1914; 1:21 - 2

[4]. 16.Lund VJ, Howard DJ. A treatment algorithm for the management of epistaxis in hereditary hemorrhagic telangiectasia. American journal of Rhinology. 1999; 13: 319 - 22.

[5]. 27.Voegels RL and others: Endoscopic ligature of the sphenopalatine artery for severe posterior epistaxis, Otolaryngol Head neck surg 124: 464, 2001.

[6]. 35.O'Donnell M, Robertson G, McGarry GW. A new bipolar diathermy probe for the outpatient management of adult acute epistaxis. Clinical Otolaryngology

[7]. Goldberg SN,Gazelle GS,Halpern EF,Ritman WJ, Muller PR, Rosenthal DL, Radiofrequency tissue abalation: importance of local temperature along the electrode tip exposure in determining lesion sape and size. Acad Radiol. 1996;3:212-8.

[8]. The Sages Manual on the Fundamental Use of Surgical Energt(FUSE) Feldman, L; Fushshuber,P.; Jones, D.B. (Eds.) 2012,XV,266p; ISBN 978-1-4614-2073-6. 